\title{
Estimativa da evapotranspiração da mangueira com base no balanço hídrico do solo'
}

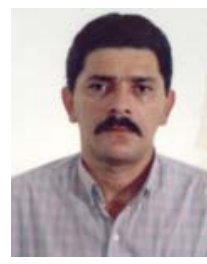

Vicente de P. R. da Silva², Pedro V. de Azevedo ${ }^{3}$, Bernardo B. da Silva ${ }^{3}$, Luís H. Bassoi ${ }^{4}$, Antonio H. de C. Teixeira ${ }^{4}$, José M. Soares ${ }^{4}$ \& José A. M. e Silva ${ }^{4}$

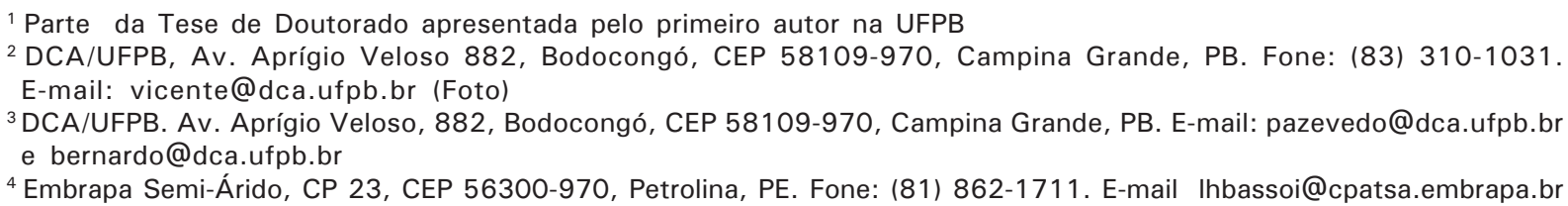

Protocolo $113-23 / 7 / 2001$

Resumo: No Projeto Irrigado de Bebedouro, em Petrolina, PE (latitude: $09^{\circ} 09^{\prime} S$, longitude: $40^{\circ} 22^{\prime} \mathrm{W}$, altitude: 365,5 m) foram avaliados, nos anos de 1998 e 1999, a distribuição radicular e o consumo de água da mangueira, cv. Tommy Atkins, com sete anos de idade, cultivada em espaçamento de $5 \times 8 \mathrm{~m}$ e irrigada por gotejamento. A profundidade efetiva das raízes foi de $1,80 \mathrm{~m}$ e o consumo médio de água foi de 4,6 e 4,1 $\mathrm{mm} \mathrm{d}^{-1}$ em 1998 e 1999, respectivamente. Os resultados indicaram que o método do balanço hídrico do solo fornece estimativa da evapotranspiração real da mangueira, para períodos de sete dias com erro de $8 \%$, que diminui a medida em que se aumenta o período analisado.

Palavras-chave: Mangifera indica L., raízes, tensiômetro, umidade do solo

\section{Evapotranspiration estimation in mango orchard using soil water balance}

\begin{abstract}
A field experiment was carried out at the Irrigation District of Bebedouro, located in the municipality of Petrolina, Brazil (latitude: 0909'S, longitude: $40^{\circ} 22^{\prime} \mathrm{W}$, altitude: $365.5 \mathrm{~m}$ ) during 1998 and 1999 to evaluate the root distribution and water consumption in a seven year old mango orchard, cv. Tommy Atkins, planted in a grid spacing of $5 \mathrm{~m}$ between plants and $8 \mathrm{~m}$ between rows, and irrigated by drippers. Effective rooting depth was around $180 \mathrm{~cm}$ and mean water consumption was 4.6 and $4.1 \mathrm{~mm} \mathrm{~d}^{-1}$ in 1998 and in 1999, respectively. Errors in soil water balance to estimate the actual evapotranspiration for seven day periods was $8 \%$.
\end{abstract}

Key words: Mangifera indica $L$, roots, tensiometer, soil moisture

\section{INTRODUÇ̃̃O}

O método do balanço hídrico do solo é satisfatório na determinação da evapotranspiração de culturas, visto que contabiliza as entradas e saídas de água no volume de controle e indica o volume de água que permanece no solo para atender às necessidades metabólicas das plantas (Reichardt, 1985). Em estudos relacionados com a interação solo-planta, o conhecimento do movimento de água no perfil do solo, drenagem profunda, movimentos de poluentes e o ajuste da curva de retenção para determinar a função condutividade hidráulica do solo, são parâmetros essenciais na elaboração do balanço hídrico (Vieira \& Castro, 1987; Pauletto et al., 1988).

A separação dos fluxos de drenagem profunda, utilizando-se perfis de umidade e de potencial hidráulico do solo, mostra-se confiável em períodos de déficit hídrico, mas falha nos períodos chuvosos, quando ocorrem aumentos no armazenamento de água no solo (Andrade et al., 1988). A variabilidade da água armazenada no solo, gradiente hidráulico, condutividade hidráulica e densidade de fluxos de água no solo, conferem coeficiente de variação da ordem de $40 \%$ no cálculo da evapotranspiração da cultura, pelo método do balanço hídrico (Villagra et al., 1995). A evaporação do solo é fundamental no cálculo do balanço hídrico, principalmente em regiões áridas e semi-áridas, onde ocorrem grandes perdas de água diretamente do solo, e menos importante em áreas úmidas, devido às freqüentes precipitações (Plauborg, 1995).

As medições tensiométricas são úteis na estimativa do gradiente de potencial hidráulico em condições de solo próximo à saturação. Além disso, a magnitude do fluxo de água na zona das raízes é função da condutividade hidráulica do solo, enquanto a direção é dependente do gradiente do potencial hidráulico (Papakyriakou \& McCaughey, 1991). A profundidade efetiva das raízes também deve ser estabelecida no balanço hídrico, pois ela representa o limite inferior do volume de solo onde são contabilizadas a entrada e a saída de água do solo (Libardi, 1995). 
Apesar do Brasil ser o quinto maior produtor mundial de manga (FAO, 1993) somente a partir do início da década de 1990 foram iniciados os trabalhos de pesquisa visando ao melhoramento genético, manejo de água e nutrientes, estudos de comportamento do sistema radicular e avaliação comportamento vegetativo e reprodutivo (Souza \& Pinto, 1996). Neste contexto e se considerando a escassez de informações sobre o manejo de água em mangueiras para o município de Petrolina, PE, o presente trabalho teve como objetivo determinar a evapotranspiração de um pomar de mangueiras irrigadas por gotejamento e avaliar a eficiência do método de balanço hídrico do solo, quando aplicado para períodos diferenciados.

\section{MATERIAL E MÉTODOS}

Este trabalho foi conduzido no Projeto Irrigado de Bebedouro, no Campo Experimental da Empresa Brasileira de Pesquisa Agropecuária (Embrapa Semi-Árido) no município de Petrolina, PE (latitude $09^{\circ} 09^{\circ} \mathrm{S}$, longitude $40^{\circ} 22^{\circ} \mathrm{W}$ e altitude $365,5 \mathrm{~m})$.

O solo da área experimental é classificado como Latossolo Vermelho-Amarelo, textura arenosa (Pereira \& Souza, 1968); seu lençol freático está localizado a $2,5 \mathrm{~m}$ de profundidade. De acordo com Ávila Netto (1997) a maior concentração de areia (74,87\%) encontra-se na camada de 0,0-0,2 m, apresentando ligeira tendência decrescente até a profundidade de $0,8 \mathrm{~m}$. Por sua vez, nas camadas de $0,0-0,4 ; 0,6-0,8$ e 1,0-1,2 m, o solo foi classificado como franco-arenoso e, nas camadas de 0,4-0,6 e 0,8-1,0 m, como franco-argilo-arenoso.

O pomar de mangueiras utilizado na condução dos experimentos foi irrigado com base nas observações da evaporação do tanque "Classe A", adotando-se o coeficiente de cultura de 0,75 entre julho a dezembro de 1998 , e de 1,0, entre junho a novembro de 1999. Em 1998 foi utilizado o sistema de irrigação por gotejamento, com duas linhas de emissores espaçadas $1,2 \mathrm{~m}$ e vazão de $3,1 \mathrm{~L} \mathrm{~h}^{-1}$, enquanto em 1999 se utilizou o mesmo sistema de irrigação, porém com as linhas de emissores espaçadas 1,8 m e vazão de 4,1 L h${ }^{-1}$. Em 1998, a lâmina d'água foi aplicada ao solo de forma contínua, no período matinal e, em 1999, se aplicou metade pela manhã e a outra metade à tarde. O período de estudo, em ambos os anos, abrangeu os seguintes estádios do ciclo produtivo do pomar de mangueiras, compreendidos entre a indução floral e a colheita: floração, queda, formação e maturação de frutos.

Em 1998, instalaram-se duas baterias de tensiômetros, em intervalos de $0,2 \mathrm{~m}$ até a profundidade de $2,2 \mathrm{~m}$, sob a copa de uma única planta, distanciadas $0,5 \mathrm{~m}$ do tronco e espaçadas $1,2 \mathrm{~m}$, enquanto em 1999 se instalaram 12 baterias, divididas em partes iguais, sob a copa de duas plantas, também distanciadas $0,5 \mathrm{~m}$ do tronco da planta e espaçadas $1,2 \mathrm{~m}$. Na condução da pesquisa em 1998, as leituras tensiométricas foram realizadas diariamente, de segunda-feira a sexta-feira, às $8 \mathrm{~h}$, e em 1999 realizaram-se três observações diárias, nos horários das 7, 12 e $17 \mathrm{~h}$, e a fenologia do pomar de mangueiras monitorada pela anotação das alterações no desenvolvimento vegetativo da planta. A variação do fator de recobrimento do solo pela área foliar da planta, foi determinada mensalmente, com base no diâmetro médio da projeção da copa das árvores no solo.
Com vistas à eliminação de valores de potencial matricial com grande variação, em 1999 foi aplicado um filtro com base no desvio-padrão $\left(\sigma_{\mathrm{j}}\right)$ das séries das observações tensiométricas de cada profundidade $\left(\mathrm{x}_{\mathrm{j}}\right)$, ou seja, foram eliminadas as observações em que $-1,5 \sigma_{\mathrm{j}} \leq \mathrm{x}_{\mathrm{j}} \leq 1,5 \sigma_{\mathrm{j}}$ de todas as profundidades das seis baterias de tensiômetros nos horários de observação. Na elaboração do balanço hídrico do solo (BH) em 1999 empregou-se a série média das 7 h, e no cálculo da drenagem/ascensão capilar (D/A) as séries dos três horários integradas no período das 7 às $12 \mathrm{~h}$, das 12 às $17 \mathrm{~h}$, das 17 às $7 \mathrm{~h}$ do dia seguinte e no período de elaboração do balanço maior que um dia.

A profundidade do sistema radicular da mangueira foi avaliada pelo método do perfil, auxilado pela análise de imagens digitais, nos anos de realização dos experimentos, para a definição da profundidade efetiva do sistema radicular a ser considerada na elaboração do balanço hídrico. Em cada ano foi aberta uma trincheira com 5,0 $\mathrm{m}$ de comprimento com $0,2 \mathrm{~m}$ de distância do tronco. As profundidades da trincheira foram de $1,6 \mathrm{~m} \mathrm{em} 1998$ e de 2,0 $\mathrm{m}$ em 1999, pois no primeiro ano constatou-se a presença de um dreno a 1,8 $\mathrm{m}$ de profundidade no local de coleta da amostragem. A parede da trincheira foi escarificada para melhor exposição das raízes e pintadas com tinta látex branca, para evidenciar o contraste com o solo. Com auxílio de um reticulado de $1,0 \times 1,0 \mathrm{~cm}$ e malha de $0,2 \times 0,2 \mathrm{~m}$, coletaram-se imagens das raízes expostas no perfil do solo, com uma máquina digital de resolução 640 x 480 pixels. A área das raízes foi obtida utilizando-se o Sistema Integrado para Análise de Raízes e Cobertura do Solo - SIARCS, e as imagens armazenadas em micromputador. Integrando-se os valores das áreas das raízes, ao longo de cada camada de solo de 0,2 $\mathrm{m}$ de espessura, determinou-se a distribuição percentual em cada uma delas, em relação ao total medido em todo o perfil de solo (Crestana et al., 1994, Bassoi et al., 1999).

O balanço hídrico do solo $(\mathrm{BH})$ foi elaborado com base na expressão (Libardi, 1995):

$$
\mathrm{P}+\mathrm{I} \pm \mathrm{D} / \mathrm{A} \pm \Delta \mathrm{h} \pm \mathrm{R}-\mathrm{ET}_{\mathrm{c}}=0
$$

em que:

$$
\begin{array}{ll}
\mathrm{ET}_{\mathrm{c}} & \text { - evapotranspiração da cultura } \\
\mathrm{P} & \text { - precipitação pluvial } \\
\mathrm{I} & \text { - irrigação } \\
\Delta \mathrm{h} & \text { - variação no armazenamento de água no perfil do solo } \\
\mathrm{R} & \text { - escoamento superficial } \\
\mathrm{D} / \mathrm{A} & \text { - drenagem profunda ou ascensão capilar }
\end{array}
$$

Todos os termos da Eq. (1) são expressos em mm por unidade de tempo. O escoamento superficial foi considerado nulo, visto que a topografia do terreno era plana, $\mathrm{P}$ foi medida com pluviômetro, I através do controle de irrigação e $\Delta \mathrm{h}$ com base no perfil de umidade do solo. A Eq. (1) é baseada no princípio de conservação de massa através da qual, segundo Singh \& Chauhan (1996), quando aplicada para um período de tempo específico, é possível determinar-se as componentes do ciclo hidrológico no sistema solo-planta.

Coletaram-se amostras deformadas de solo, em intervalos de $0,2 \mathrm{~m}$ até a profundidade de $2,2 \mathrm{~m}$, para a determinação da curva de retenção de água no solo no Laboratório de Solos da Embrapa Semi-Árido, pelo método da câmara de Richards, 
nas pressões de 10,$13 ; 30,39 ; 50,66 ; 70,93 ; 101,32 ; 506,62$ e $1.519,87 \mathrm{KPa}$. A extração da umidade das amostras de solo, em estufa à temperatura de $105^{\circ} \mathrm{C}$, e a determinação da densidade aparente do solo, também foram realizadas no laboratório. No interior da parcela estudada foi aberta uma trincheira com 2,3 m de profundidade, 1,0 $\mathrm{m}$ de largura e 2,0 $\mathrm{m}$ de comprimento, para extração de amostras indeformadas de solo, com três repetições, em intervalos de 0,2 $\mathrm{m}$ até a profundidade de 2,2 m. Essas amostras foram utilizadas para determinação da condutividade hidráulica saturada, com permeâmetro de carga constante, no Laboratório de Irrigação e Salinidade da Universidade Federal da Paraíba, em Campina Grande, PB.

O fluxo descendente (D) ou ascendente (A) cruzando o limite inferior do volume de solo considerado, foi obtido pela equação de Darcy-Buckingham, escrita para fluxo vertical (Libardi, 1995):

$$
\frac{\mathrm{D}}{\mathrm{A}}=-\left[\overline{\mathrm{K}}(\theta) \frac{\partial \phi_{\mathrm{t}}}{\partial \mathrm{Z}}\right]
$$

em que:

$\mathrm{D} / \mathrm{A}$ - densidade de fluxo da água no solo, $\mathrm{cm}^{3} \mathrm{~cm}^{-2} \mathrm{~d}^{-1}$

$\overline{\mathrm{K}}(\theta)$ - condutividade hidráulica média do solo, $\mathrm{cm} \mathrm{d}^{-1}$

$\partial \phi_{t} / \partial Z$ - gradiente vertical do potencial hidráulico, $\mathrm{cm} \mathrm{cm}^{-1}$

$\phi_{t} \quad$ - potencial hidráulico da água no solo, $\mathrm{cm}$ de coluna de água

Z - coordenada vertical, $\mathrm{cm}$

Integrando-se os valores de $\mathrm{D} / \mathrm{A}$ para um período de tempo, obteve-se o seu valor total para o referido intervalo. O gradiente do potencial hidráulico foi calculado considerando-se os valores dos potenciais acima e abaixo de determinada profundidade, dividido pela distância entre eles. Pela equação de Darcy-Buckingahm, valores positivos e negativos do gradiente indicam fluxo de água descendente e ascendente, respectivamente.

O conteúdo de umidade no solo (em base volumétrica) foi obtida pela expressão (van Genuchten, 1980):

$$
\theta=\theta_{\mathrm{r}}+\frac{\theta_{\mathrm{s}}-\theta_{\mathrm{r}}}{\left[1+\left|\alpha \phi_{\mathrm{m}}\right|^{\mathrm{n}}\right]^{\mathrm{m}}}
$$

em que:

$\theta_{\mathrm{r}} \quad$ - umidades volumétricas residual, $\mathrm{m}^{3} \mathrm{~m}^{-3}$

$\theta_{\mathrm{s}} \quad$ - umidades volumétricas de saturação, $\mathrm{m}^{3} \mathrm{~m}^{-3}$

$\phi_{\mathrm{m}} \quad$ - potencial matricial, $\mathrm{cm}$ de coluna de água

$\alpha, \mathrm{n}$ e m - constantes empíricas, determinadas pelo programa

Curvaret (Dourado Neto \& van Lier, 1993)

A condutividade hidráulica para o solo não saturado $K(\theta)$ foi determinada pela equação (van Genuchten, 1980):

$$
\mathrm{K}(\theta)=\mathrm{K}_{0} \omega^{l}\left[1-\left(1-\omega^{\frac{1}{\mathrm{~m}}}\right)^{\mathrm{m}}\right]^{2}
$$

em que:

$$
\begin{aligned}
& \mathrm{K}_{0} \text { - condutividade hidráulica do solo saturado } \\
& \text { l - parâmetro empírico que, segundo Mualen (1976), é } \\
& \text { igual a } 0,5 \text { para a maioria dos solos } \\
& \text { m }-1-1 / n \\
& \mathrm{w}-\frac{\theta-\theta_{\mathrm{r}}}{\theta_{\mathrm{s}}-\theta_{\mathrm{r}}}
\end{aligned}
$$

O potencial total de água no solo $\phi_{\mathrm{t}}$ foi obtido pela expressão (Libardi, 1995):

$$
\phi_{\mathrm{t}}=\phi_{\mathrm{m}}+\phi_{\mathrm{z}}
$$

em que:

$$
\begin{aligned}
& \phi_{\mathrm{m}} \quad \begin{array}{l}
\text { - potencial matricial de água no solo, } \mathrm{cm} \text { de coluna de } \\
\text { água }
\end{array} \\
& \phi_{\mathrm{z}} \quad \begin{array}{l}
\text { - potencial gravitacional de água no solo, } \mathrm{cm} \text { de coluna } \\
\text { de água. }
\end{array}
\end{aligned}
$$

As componentes de pressão e osmótica não foram consideradas, visto que se tornam importantes apenas quando o solo se encontra saturado e a concentração salina é alta (Reichardt, 1985; du Plessis, 1985). A componente gravitacional representa a distância em relação à superfície do solo $(\mathrm{cm})$ e a matricial foi obtida com base nas medições tensiométricas, pela expressão (Libardi, 1995):

$$
\phi_{\mathrm{m}}=-12,6 \mathrm{~h}_{\mathrm{Hg}}+\mathrm{h}_{\mathrm{c}}+\mathrm{h}_{\mathrm{p}}
$$

em que:

$\mathrm{h}_{\mathrm{Hg}}$ - altura da coluna de mercúrio a partir do nível da cuba, $\mathrm{cm}$

$\mathrm{h}_{\mathrm{c}} \quad$ - altura do nível da cuba em relação ao solo, $\mathrm{cm}$

$\mathrm{h}_{\mathrm{p}}$ - profundidade da cápsula porosa, $\mathrm{cm}$

O armazenamento de água no solo foi calculado pela regra do trapézio, considerando-se que as medidas foram realizadas em intervalos igualmente espaçados, desde a superfície $(z=0)$ até a profundidlade de interesse $(\mathrm{z}=\mathrm{L})$ de acordo com a seguinte equação (Libardi, 1995):

$$
\mathrm{h}_{\mathrm{L}}=\int_{0}^{\mathrm{L}} \theta(\mathrm{z}) \mathrm{dz}=\left[0,50 \theta(\mathrm{z})+\sum_{\mathrm{i}=1}^{\mathrm{n}-1} \theta\left(\mathrm{z}_{\mathrm{i}}\right)+0,50 \theta\left(\mathrm{z}_{\mathrm{n}}\right)\right] \Delta \mathrm{z}
$$

em que:

$\theta \quad$ - umidade média do perfil do solo considerado, $\mathrm{cm}^{3} \mathrm{~cm}^{-3}$

$\Delta \mathrm{z}$ - espessura da camada de solo, $\mathrm{cm}$

Assume-se que, pela proximidade em $z=0$, a umidade é a mesma que em $z=z_{1}$ e em $z=L$ a mesma que $z=z_{n}$. A variação do armazenamento de água no solo $(\mathrm{mm})$ durante os períodos de tempo considerados, foi obtida pela expressão:

$$
\Delta \mathrm{h}=\mathrm{h}_{\mathrm{t}}-\mathrm{h}_{\mathrm{t}-1}
$$

em que:

$\mathrm{h}_{\mathrm{t}} \quad$ - armazenamento de água no perfil do solo no instante $\mathrm{t}$

$\mathrm{h}_{\mathrm{t}-1} \quad$ - armazenamentos de água no perfil do solo no instante $\mathrm{t}-1$. 
Para se determinar a porcentagem da área molhada ao longo de um plano horizontal de $0,3 \mathrm{~m}$ abaixo da superfície do solo, por duas linhas de gotejadores, abriu-se uma trincheira de $3,0 \mathrm{~m}$ de largura e 4,5 m de comprimento; assim, a porcentagem da área molhada (Pw) foi determinada (Keller \& Bliesner, 1990):

$$
\mathrm{P}_{\mathrm{w}}=\frac{\mathrm{N}_{\mathrm{p}} \mathrm{S}_{\mathrm{e}}^{\prime}\left(\mathrm{S}_{\mathrm{e}}^{\prime}+\mathrm{w}\right) / 2}{\mathrm{~S}_{\mathrm{p}} \mathrm{S}_{\mathrm{r}}} 100
$$

em que:

$\mathrm{N}_{\mathrm{p}}$ - número de emissores por planta

$\mathrm{S}_{\mathrm{e}}{ }_{\mathrm{e}} \quad$ - espaçamento ótimo entre emissores $\left(\mathrm{S}_{\mathrm{e}}{ }_{\mathrm{e}}=0,8 \mathrm{w}\right)$

W - diâmetro da área circular úmida de um único emissor

$\mathrm{S}_{\mathrm{p}} \quad$ - espaçamento entre plantas na fileira

$\mathrm{S}_{\mathrm{r}} \quad$ - espaçamento entre fileiras.

Em condições de campo em que $\mathrm{S}_{\mathrm{e}}<\mathrm{S}$ ', , substituiu-se na Eq. (9) $S^{\prime}$ e por $S_{e}$, em que $S_{e}$ é o espaçamento entre emissores ao longo da linha lateral. Todos os termos da Eq. (9) são expressos emm.

O erro atribuído à determinação do balanço hídrico do solo no intervalo de tempo $t(\varepsilon \%$ ) foi obtido pela expressão (Mickson et al., 1997):

$$
\varepsilon(\%)=\frac{\left(S T_{0}+\sum_{j=0}^{t} R_{j}-\sum_{j=0}^{t} Q_{j}-\sum_{j=0}^{t} E T c_{j}\right)-S T_{f}}{S T_{f}}
$$

em que:

$\mathrm{ST}_{\mathrm{o}}$ - umidade armazenada no solo no instante inicial, $\mathrm{mm}$

$\mathrm{ST}_{\mathrm{f}}$ - umidade armazenada no solo no instante final, $\mathrm{mm}$

$R_{j} \quad$ - precipitação e/ou a irrigação acumulada, $\mathrm{mm}$

$\mathrm{Q}_{\mathrm{j}} \quad$ - drenagem acumulada, mm

$\mathrm{ET}_{\mathrm{cj}}$ - evapotranspiração do pomar de mangueiras acumulada no período de elaboração do balanço, $\mathrm{mm}$.

\section{RESULTADOS E DISCUSSÃO}

O sistema radicular da mangueira atingiu as profundidades de 1,6 e 2,0 m, em 1998 e 1999, respectivamente, e apresentou distribuição homogênea ao longo do perfil do solo (Tabela 1), sendo que 81,3 e $79,3 \%$ das raízes estiveram presentes, respectivamente, nas camadas de solo de 0,2 a 1,4 m em 1998 e de $0,4 \mathrm{a} \mathrm{1,4} \mathrm{m}$ de profundidade, em 1999. Devido à presença de um dreno localizado à profundidade de $1,8 \mathrm{~m}$, na linha de planta analisada em 1998, a profundidade do sistema radicular foi menor que a do ano seguinte. Para a mangueira cv. Haden sobre porta-enxerto Carlota, com cinco anos de idade, cultivada em espaçamento de 10 x 10 m em um solo de textura argilosa, Santos (1997) constatou também considerável presença de raiz ao longo do perfil de solo, ou seja, 32,3;21,8; 19,7; 17,5 e 8,7\%, respectivamente, nas camadas de $0-0,25 ; 0,25-0,50 ; 0,50-0,75$; 0,75-1,0, e 1,0-1,25 m de profundidade. Choudhury \& Soares (1992) também observaram a presença de raízes de mangueira cv. Tommy Atkins, com oito anos de idade, ao longo da profundidade de $1 \mathrm{~m}$, em Latossolo Vermelho-Amarelo, textura arenosa. No presente trabalho, consideraram-se as profundidades de 1,6 e 1,8 m, respectivamente, em 1998 e 1999, como os limites inferiores do volume de solo para fins de cálculo do balanço hídrico.

As componentes do balanço hídrico do solo dos experimentos de 1998 e 1999 são apresentadas na Tabela 2, com a evapotranspiração corrigida pela relação entre a área de molhamento e a área de projeção da copa da planta no solo. Nesses anos, os valores de $\mathrm{P}_{\mathrm{w}}$ foram de 16,4 e 19,0 $\mathrm{m}^{2}$, respectivamente; a área média da projeção da copa da mangueira no solo apresentou pequena variação ao longo dos experimentos, mantendo-se ao redor de $34 \mathrm{~m}^{2}$, devido à poda realizada no início de cada ciclo; desta forma, a correção, que em 1998 e 1999 foi, respectivamente, de 0,48 e 0,56, variou em função da vazão dos emissores e distanciamento das linhas de gotejadores.

Os dados de tensiometria em 1998 não permitiram a determinação do balanço hídrico no período de floração, porém no período de 25/08 a 23/11/1998, a lâmina de irrigação, somada ao total pluviométrico, resultou em 800,3 mm d'água aplicada ao solo, enquanto a evapotranspiração no período foi de 411,4 mm (Tabela 2). O lençol freático contribuiu com 23,1 mm na forma de ascensão capilar, predominantemente no período de 25/08 a 29/09/1998. Após essas datas e apesar de pequena, ocorreu percolação até 23/11/1998. A evapotranspiração diária média foi de 4,6 $\mathrm{mm} \mathrm{d}^{-1}$, com taxas mínimas no início e no final do período, e máxima de $5,5 \mathrm{~mm} \mathrm{~d}^{-1}$ no estádio fenológico de formação de frutos, que correspondeu ao período de maior desenvolvimento vegetativo das plantas.

O período de elaboração do balanço hídrico em 1999 foi mais longo, englobando todos os estádios fenológicos do ciclo produtivo do pomar de mangueiras, que em 1998, quando as medições tensiométricas foram realizadas apenas uma vez por dia e a drenagem/ascensão capilar calculada para o mesmo período de elaboração do balanço (uma semana) fazendo com que o método apresentasse, nessas condições, pouca precisão. O balanço hídrico do solo em 1999, elaborado no mesmo período de tempo de 1998 (90 dias), indicou uma evapotranspiração média de 4,9 $\mathrm{mm} \mathrm{d}^{-1}$, que se aproxima do valor de 4,6 $\mathrm{mm} \mathrm{d}^{-1}$ obtido no ano anterior. Em 1999 a drenagem profunda totalizou $178,3 \mathrm{~mm}$, a ascensão capilar apenas $2,7 \mathrm{~mm}$ e a média semanal da irrigação foi de 54,5 mm totalizando, no período, 1.144,5 mm. Este aumento da drenagem foi atribuído ao aumento da vazão dos emissores, de 3,1 para 4,1 $\mathrm{L} \mathrm{h}^{-1}$, e do coeficiente de cultura, de 0,75 para 1,0, em 1999 .

Tabela 1. Distribuição percentual da área de raízes exposta no perfil de solo a 0,2 $\mathrm{m}$ de distância do caule da mangueira, no Projeto Irrigado de Bebedouro, em Petrolina, PE

\begin{tabular}{ccccccccccccc} 
Ano & \multicolumn{10}{c}{ Camada de Solo - m } \\
\cline { 2 - 10 } & $0-0,2$ & $0,2-0,4$ & $0,4-0,6$ & $0,6-0,8$ & $0,8-1,0$ & $1,0-1,2$ & $1,2-1,4$ & $1,4-1,6$ & $1,6-1,8$ & $1,8-2,0$ \\
\hline 1998 & 9,8 & 19,6 & 16,1 & 8,5 & 10,4 & 12,8 & 13,8 & 8,9 & - & - \\
1999 & 5,4 & 5,7 & 13,4 & 20,1 & 16,2 & 15,3 & 14,3 & 9,7 & 6,9 & 6,1 \\
\hline
\end{tabular}


Tabela 2. Variação no armazenamento de água no solo $(-\Delta \mathrm{h})$, irrigação (I), precipitação pluvial $(\mathrm{P})$, drenagem/ascensão capilar (D/A), e evapotranspiração real $\left(\mathrm{ET}_{\mathrm{c}}\right)$ do pomar de mangueiras, em Petrolina, PE, em 1998 e 1999

\begin{tabular}{|c|c|c|c|c|c|c|}
\hline \multirow{2}{*}{ Período } & \multirow{2}{*}{$\mathrm{EF}^{*}$} & $-\Delta \mathrm{h}$ & I & $\mathrm{P}$ & $\mathrm{D} / \mathrm{A}$ & \multirow{2}{*}{$\begin{array}{c}\mathrm{ET}_{\mathrm{c}}^{* *} \\
\left(\mathrm{mmd}^{-1}\right)\end{array}$} \\
\hline & & \multicolumn{4}{|c|}{$\mathrm{mm}$} & \\
\hline \multicolumn{7}{|c|}{ Ano de 1998} \\
\hline $25 / 08-01 / 09$ & 2 & 3,8 & 64,0 & 0,0 & 6,5 & 5,1 \\
\hline $02 / 09-08 / 09$ & 2 & 4,9 & 51,1 & 0,0 & 0,3 & 3,9 \\
\hline $09 / 09-15 / 09$ & 2 & $-2,7$ & 66,4 & 0,6 & 4,6 & 4,7 \\
\hline $16 / 09-22 / 09$ & 3 & 1,8 & 49,9 & 0,0 & 7,7 & 4,1 \\
\hline $23 / 09-29 / 09$ & 3 & 4,4 & 51,8 & 0,0 & 5,0 & 4,9 \\
\hline $29 / 09-05 / 10$ & 3 & 6,3 & 55,6 & 0,0 & $-0,8$ & 4,2 \\
\hline $06 / 10-13 / 10$ & 3 & 6,4 & 73,3 & 0,0 & $-0,4$ & 4,8 \\
\hline $14 / 10-20 / 10$ & 3 & $-2,3$ & 74,7 & 0,0 & 1,5 & 5,1 \\
\hline $21 / 10-27 / 10$ & 3 & 1,7 & 78,5 & 0,0 & $-0,1$ & 5,5 \\
\hline $28 / 10-03 / 11$ & 3 & 6,4 & 48,3 & 0,0 & 0,1 & 3,8 \\
\hline $04 / 11-16 / 11$ & 4 & 6,4 & 83,9 & 34,0 & $-0,3$ & 4,6 \\
\hline $17 / 11-23 / 11$ & 4 & $-6,9$ & 49,8 & 18,4 & $-1,0$ & 4,1 \\
\hline Média/Total & - & ${ }^{2} 30,2$ & ${ }^{1} 62,3$ & ${ }^{2} 53,0$ & ${ }^{2} 23,1$ & 14,6 \\
\hline \multicolumn{7}{|c|}{ Ano de 1999} \\
\hline $31 / 05-17 / 06$ & 1 & 34,0 & 0,0 & 0,0 & 1,0 & 2,1 \\
\hline $18 / 06-29 / 06$ & 1 & 26,5 & 0,0 & 0,0 & 0,0 & 2,4 \\
\hline $30 / 06-12 / 07$ & 2 & 6,1 & 25,8 & 0,4 & 1,0 & 2,8 \\
\hline $13 / 07-19 / 07$ & 2 & $-18,9$ & 55,7 & 1,2 & 0,7 & 3,1 \\
\hline $20 / 07-26 / 07$ & 2 & $-22,5$ & 64,6 & 0,5 & $-5,2$ & 3,0 \\
\hline $27 / 07-02 / 08$ & 3 & $-14,8$ & 75,1 & 0,0 & $-4,1$ & 4,5 \\
\hline $03 / 08-09 / 08$ & 3 & $-0,9$ & 66,1 & 1,1 & $-22,6$ & 3,5 \\
\hline $10 / 08-16 / 08$ & 3 & 12,7 & 61,1 & 0,0 & $-23,5$ & 4,0 \\
\hline $17 / 08-23 / 08$ & 3 & $-7,0$ & 78,5 & 0,2 & $-24,5$ & 3,8 \\
\hline $24 / 08-30 / 08$ & 3 & $-3,3$ & 75,5 & 0,0 & $-31,1$ & 3,3 \\
\hline $31 / 08-06 / 09$ & 3 & 12,2 & 81,3 & 0,0 & $-20,2$ & 5,9 \\
\hline $07 / 09-13 / 09$ & 3 & 10,4 & 52,7 & 0,0 & $-12,6$ & 4,0 \\
\hline $14 / 09-20 / 09$ & 3 & 19,2 & 44,7 & 0,0 & $-7,5$ & 4,5 \\
\hline $21 / 09-27 / 09$ & 3 & $-1,1$ & 34,0 & 30,4 & $-3,1$ & 4,8 \\
\hline $28 / 09-04 / 10$ & 4 & $-3,0$ & 54,4 & 0,0 & $-6,4$ & 3,6 \\
\hline $05 / 10-11 / 10$ & 4 & 10,2 & 73,9 & 0,4 & $-3,9$ & 7,9 \\
\hline $12 / 10-18 / 10$ & 4 & 6,0 & 60,7 & 0,8 & $-3,3$ & 5,7 \\
\hline $19 / 10-25 / 10$ & 4 & 1,4 & 71,3 & 0,0 & $-1,8$ & 5,7 \\
\hline $26 / 10-01 / 11$ & 4 & $-5,8$ & 73,2 & 6,3 & $-4,3$ & 5,5 \\
\hline $02 / 11-08 / 11$ & 4 & 4,4 & 45,3 & 0,0 & $-2,9$ & 3,7 \\
\hline $09 / 11-15 / 11$ & 5 & $-0,7$ & 50,6 & 0,0 & $-1,3$ & 3,5 \\
\hline Média/Total & - & ${ }^{2} 65,1$ & ${ }^{1} 54,5$ & ${ }^{2} 41,3$ & ${ }^{2} 75,6$ & ${ }^{2} 4,1$ \\
\hline
\end{tabular}

"EF - Estádio Fenológico - 1, 2, 3, 4 e 5 representam, respectivamente, os estádios fenológicos de Floração, Queda de Frutos, Formação de Frutos, Maturação e Colheita

*" Os valores de ET de 1998 e 1999 são multiplicados, respectivamente, pelos fatores de correção de 0,48 e de 0,56

${ }^{1}=$ Média ${ }^{2}=$ Total

O excesso d'água causado pela irrigação e precipitação pluvial em 1999, não utilizado nos processos metabólicos da planta, contribuiu para a drenagem profunda. Neste ano, a evapotranspiração do pomar de mangueiras aumentou sistematicamente de $2,4 \mathrm{~mm} \mathrm{~d}^{-1}$, no início da floração, quando ainda não tinha sido iniciada a irrigação, para $7,9 \mathrm{~mm} \mathrm{~d}^{-1}$, no final do estádio fenológico de formação de frutos decrescendo, em seguida, para atingir $3,5 \mathrm{~mm} \mathrm{~d}^{-1}$ no estádio de maturação de frutos.

A drenagem profunda atingiu os valores mais elevados, que variaram de 22,8 a 12,6 mm por semana, com máximo de $31,1 \mathrm{~mm}$, no período de 3 de agosto a 13 de setembro. Em 1998 a ascensão capilar e a drenagem representaram, respectivamente, 3,21 e $0,32 \%$ da lâmina total de água que o volume de solo considerado recebeu (irrigação e precipitação pluvial) e em 1999 o fluxo ascendente foi de $0,23 \%$ e a drenagem profunda $16 \%$ da lâmina total de água. Por outro lado, em 1999 , com $\mathrm{K}_{\mathrm{c}}=1,0$, ocorreu drenagem acentuada em praticamente todo o ciclo produtivo, excetuando-se o período anterior à irrigação. Mesmo para períodos semanais, de acordo com a disponibilidade dos dados de umidade do solo, o balanço hídrico do solo é mais preciso quando a drenagem profunda e a ascensão capilar são obtidas para períodos iguais ou inferiores a um dia (Libardi, 1995). Durante o ciclo produtivo do pomar de mangueiras, em 1999 a evapotranspiração totalizou $612,4 \mathrm{~mm}$, com média de $4,1 \mathrm{~mm} \mathrm{~d}^{-1}$. A lâmina d'água aplicada ao solo por irrigação foi de $1.144,5 \mathrm{~mm}$ e a pluviometria no período foi de $41,3 \mathrm{~mm}$. A drenagem profunda para o lençol freático no período estudado foi de $178,3 \mathrm{~mm}$, com valores mínimos no início e final do ciclo produtivo, e máximos na fase intermediária. A densidade de fluxo de água no solo, estimada pela equação de Darcy-Buckingham, foi ascendente entre 31 de maio e 19 de julho, com ascensão capilar de 2,7 mm; posteriormente, devido o início da irrigação, houve predominância de fluxo de água descendente.

A Figura 1 exibe o comportamento temporal do gradiente de potencial hidráulico do solo, em camadas de $0,2 \mathrm{~m}$, até a profundidade de 2,0 m. Observam-se gradientes de potencial hidráulicos negativos, no período entre 03/05/1999 a 12/07/1999, nas camadas de solo de 0,2-0,6 m e de 0,4-0,8 m, e positivos, a partir desta última data, até 15/11/1999, nas camadas de solo de 0,6-1,0 m e de 0,8-1,2 m (Figura 1A). A partir de 27/9/1999 ocorreram gradientes do potencial hidráulico negativos entre 1,0 e 1,4 e entre 1,2 e 1,6 m de profundidade, indicando movimento de água ascendente, nas profundidades de 1,2 e 1,4 m (Figura 1B). Essa última camada contribuiu para o processo de evapotranspiração, devido à distribuição radicular ao longo de todo o perfil de solo analisado, e para o aumento da evapotranspiração da cultura entre 5 de outubro a 1 de novembro, durante o estádio da maturação dos frutos (Tabela 2).

Os somatórios das componentes do balanço hídrico do solo em 1999 e o percentual de erros, por período de realização do balanço, são apresentados na Tabela 3 , na qual se observa que o maior nível de erro foi associado ao balanço hídrico realizado para períodos de um dia. Sendo o balanço hídrico do solo realizado para períodos intermediários de 2,3 e 5 dias, o percentual de erro atribuído ao método foi de 16,$4 ; 17,4$ e 20,5\%, o qual não decresceu necessariamente com o aumento do período de elaboração do balanço; entretanto, quando o balanço hídrico foi realizado para períodos iguais ou superiores a uma semana (7, 10 e 15 dias) o percentual de erro se manteve bastante reduzido, variando de 8,0 a 7,0\%. Mickson et al. (1997) utilizaram a mesma metodologia e encontraram um nível de erro na elaboração do balanço hídrico variando de 0,5 a 45,6\%, em condições diferentes de tratamento, o qual foi atribuído às incertezas das medições tensiométricas. Muito embora os balanços hídricos elaborados para períodos superiores a uma semana tenham exibido percentual de erro inferior, foi utilizado o período de sete dias na estimativa da $\mathrm{ET}_{c}$, visto que a utilização da metodologia para períodos maiores pode não contemplar as alterações fenológicas nos subperíodos do ciclo produtivo da planta. 
A.

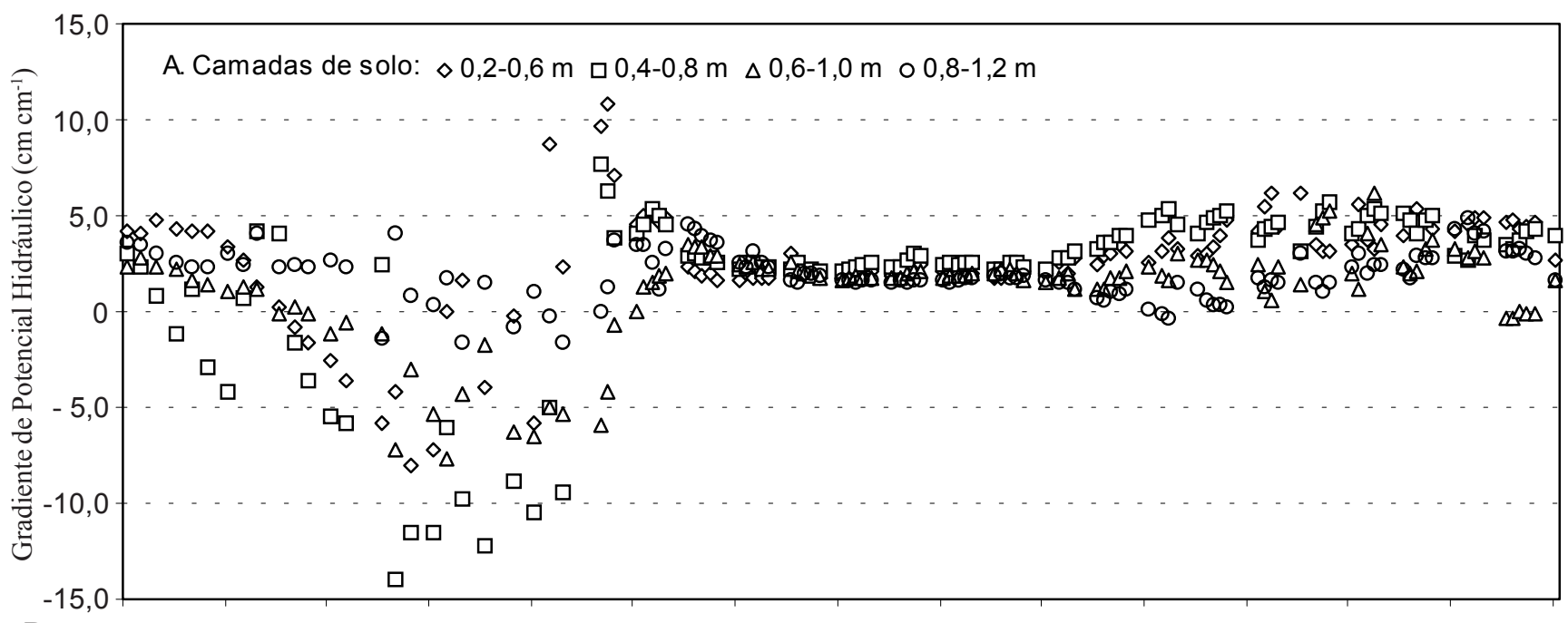

B.

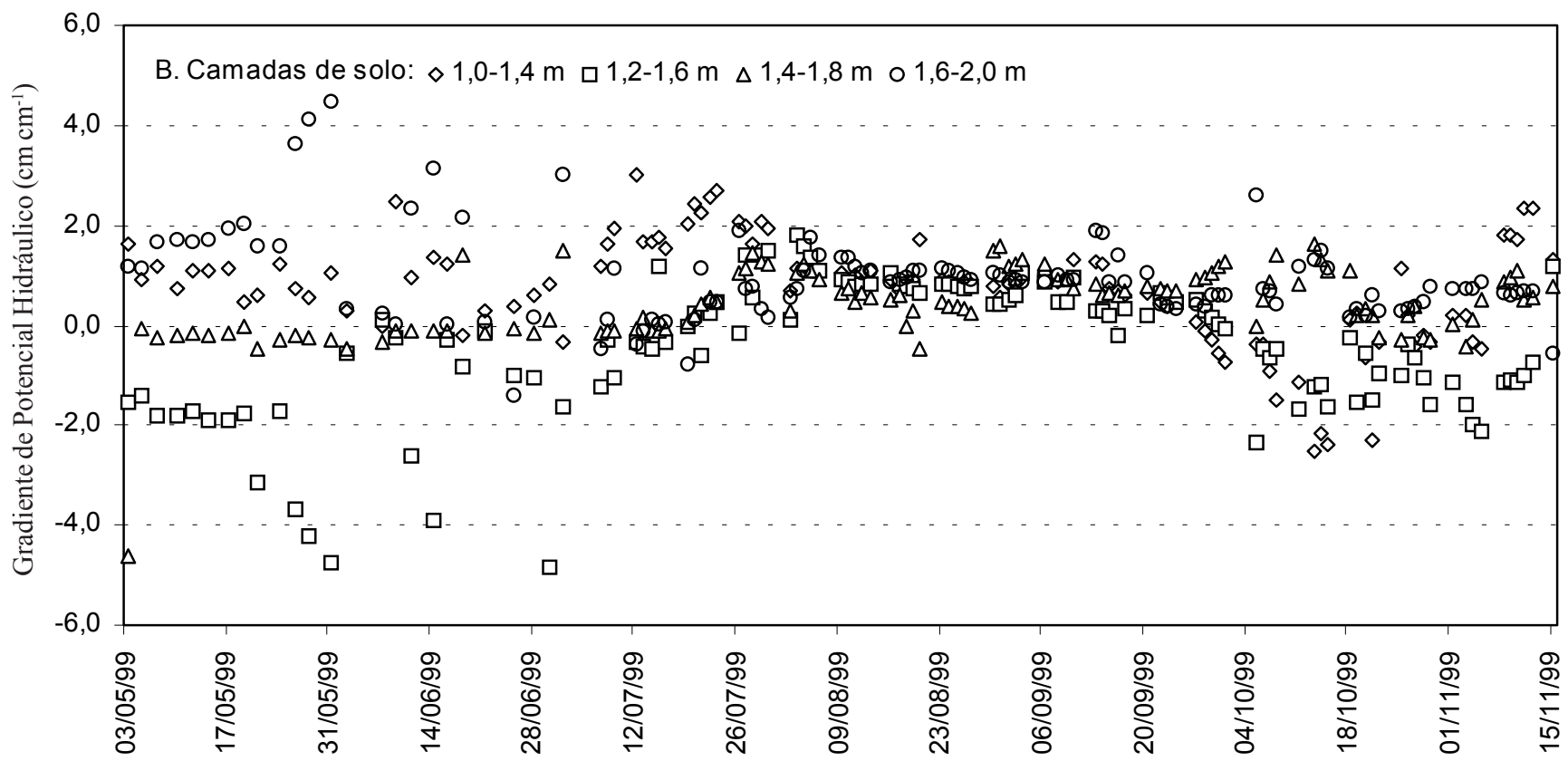

Figura 1. Comportamento temporal do gradiente de potencial hidráulico nas camadas de solo: A) 0,2-0,6; 0,4-0,8;0,6-1,0;0,8-1,2 m; B) 1,0-1,4; 1,2-1,6; 1,4-1,8; 1,6-2,0 m, sob a mangueira, em Petrolina, PE, em 1999

Tabela 3. Percentual de erros, $\varepsilon$ (\%) por período de realização do balanço hídrico do solo, conteúdo de umidade no solo nos instantes inicial $\left(\mathrm{ST}_{0}\right)$ e final $\left(\mathrm{ST}_{\mathrm{f}}\right)$, precipitação pluvial e/ou irrigação $\left(\Sigma \mathrm{R}_{\mathrm{j}}\right)$, drenagem/ascensão $\left(\Sigma \mathrm{Q}_{\mathrm{j}}\right)$ e evapotranspiração $\left(\Sigma E_{c}\right)$ acumulada no período de 13/07 a 11/11/1999

\begin{tabular}{|c|c|c|c|c|c|c|}
\hline \multirow{2}{*}{$\begin{array}{l}\text { Intervalo de } \\
\text { Tempo (d) }\end{array}$} & $\mathrm{ST}_{0}$ & $\mathrm{ST}_{\mathrm{f}}$ & $\Sigma \mathrm{R}_{\mathrm{j}}$ & $\Sigma \mathrm{Q}_{\mathrm{j}}$ & $\Sigma \mathrm{ET}_{\mathrm{c}}$ & \multirow{2}{*}{$\begin{array}{c}\varepsilon \\
(\%)\end{array}$} \\
\hline & \multicolumn{5}{|c|}{$\mathrm{mm}$} & \\
\hline 1 & 252 & 258,7 & 1134,9 & 177,7 & 6 & 41,7 \\
\hline 2 & 25 & 258,7 & 113 & 17 & & 16,4 \\
\hline 3 & 252,0 & 258,7 & 1134,9 & 177,7 & 905,4 & 17,4 \\
\hline 5 & 252,0 & 258,7 & 1134,9 & 177,7 & 897,4 & 20,5 \\
\hline 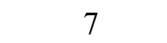 & & 258,7 & 113 & 177,7 & 97 & 8,0 \\
\hline 10 & 252,0 & 258,7 & 1134,9 & 177,7 & 968,7 & 7,0 \\
\hline 15 & 252,0 & 258,7 & 1134,9 & 177,7 & 968,6 & 6,9 \\
\hline
\end{tabular}

Face ao baixo nível de erro associado ao método, o balanço hídrico do solo mostrou-se eficiente na determinação da evapotranspiração da cultura da mangueira, quando elaborado para período de sete dias. Resultados similares foram encontrados por Trambouze et al. (1998), os quais observaram que método do balanço hídrico do solo somente oferece estimativas precisas da evapotranspiração quando elaborado para períodos de uma semana. Para períodos inferiores, as medições tensiométricas podem não refletir efetivamente o volume d'água armazenado no solo, devido ao tempo necessário para a cápsula porosa do instrumento entrar em equilíbrio com o solo (tempo de resposta do instrumento) e, ainda, pelo fato dos tensiômetros não acusarem variações de umidade em solos acima da capacidade de campo, situação freqüente na camada superficial de solo, logo após a irrigação. Por estas razões, o balanço hídrico do solo elaborado para os períodos de 1,2, 3 e 5 dias apresentou erros apreciáveis, sugerindo que o método não funciona adequadamente para períodos curtos. Papakyriakou \& McCaughey (1991) observaram que o período máximo para aplicação do balanço hídrico, com confiabilidade de $90 \%$, é de treze dias e que a probabilidade de erros é menor para períodos com pouca precipitação e alta taxa evaporativa. 


\section{CONCLUSÕES}

1. O uso do método do balanço hídrico do solo para estimativa da evapotranspiração real da cultura da mangueira, cv. Tommy Atkins, mostrou-se eficiente nas condições de clima e solo do Projeto Irrigado de Bebedouro, em Petrolina, PE.

2. O método do balanço hídrico do solo não deve ser aplicado para períodos inferiores a uma semana, nas condições de solo e clima da área estudada.

3. Os valores de $\mathrm{ET}_{\mathrm{c}}$ foram mínimos no início e no final do ciclo de produção da mangueira, sendo que os maiores foram determinados no período de formação de frutos.

\section{AGRADECIMENTOS}

Os autores expressam seu reconhecimento ao Conselho Nacional de Desenvolvimento Científico e e Tecnológico (CNPq), através do Programa Nordeste de Pós Graduação e Pesquisa, Processos 521198/98-4 e 521278/98-8, pela colaboração financeira na execução deste trabalho.

\section{LITERATURA CITADA}

Andrade, C.L.T.; Sediyama, G.C.; Couto, L; Sans, L.M.A.; Ferreira, P.A. Balanço hídrico num Latossolo VermelhoEscuro álico cultivado com milho com irrigação por aspersão. Agronômica Ceres, São Paulo, v.35, p.89-104, 1988.

Ávila Netto, J. Necessidades hídricas da videira européia. Campina Grande: DCA/CCT/UFPB, 1997, 85p. Dissertação Mestrado

Bassoi, L.H.; Silva, J.A.M.; Alencar, C.M. de.; Jorge, L.A. de C.; Hopmans, J.W. Digital image analysis of root distribution towards improved irrigation water and soil management. In: ASAE Annual Meeting, 1999, Toronto. Papers... Toronto: ASAE, 1999, 6p. Paper 992225

Choudhury, E.N.; Soares, J.M. Comportamento do sistema radicular de fruteiras irrigadas. Mangueira em solo arenoso sob irrigação por aspersão subcopa. Revista Brasileira de Fruticultura, Cruz das Almas, v.14, n.3, p.169-176, 1992.

Crestana, S.; Guimarães, M.F.; Jorge, L.A.C.; Ralish, R.; Tozzi, C.L.; Torre, A.; Vaz, C.M.P. Avaliação da distribuição de raízes no solo auxiliada por processamento de imagens digitais. Revista Brasileira de Ciência do Solo, Campinas, v.18, p.365-371, 1994.

Dourado Neto, D; van Lier, Q.J. Estimativa do armazenamento de água no solo para realização do balanço hídrico. Revista Brasileira de Ciências do Solo, Campinas, v.17, n.1, p.9-15, 1993.

du Plessis, H.M. Evapotranspiration of citrus as affected by soil water deficit and soil salinity. Irrigation Science, Heidelberg, v.6, p.51-61, 1985.

FAO Yearbook Annuairi Production. v. 47, Rome, 1993, 254p.

Keller, J.; Bliesner, R.D. Sprinkle and trickle irrigation. 1. ed. New York: Chapman \& Hall, 1990, 321p.
Libardi, P.L. Dinâmica da água no solo. 1. ed. Piracicaba: Departamento de Física e Meteorologia (ESALQ/USP). 1995. 497p.

Mickson, S.B.; Yomota, A; Miura, T. Water balance of field plots planted with soybean and pumpkin. Trasactions of the ASAE, St. Joseph, v.40, n.4, p.899-909, 1997.

Mualen, Y.A. A new model for predicting the hydraulic conductivity of unsaturated porus media. Water Resources Research, Washington, v.12, n.3, p.513-522, 1976.

Papakyriakou, T.N.; McCaughey, J.H. An evaluation of the water balance technique for the estimation of evapotranspiration for a mixed forest. Canadian Journal of Forest Research, Canada, v.21, n.11, p.1622-1631, 1991.

Pauletto, E.A.; Libardi, P.L.; Manfron, P.A.; Soares, S.O. Determinação da condutividade hidráulica de solos a partir da curva de retenção de água. Revista Brasileira de Ciência do Solo, Campinas, v.12, n.1, p.189-195, 1988.

Pereira, J.M.; Souza, R.A. Mapeamento detalhado da área da Barra de Bebedouro. Petrolina, SUDENE, 1968, 57p. Mimeografado

Plauborg, F. Evaporation from bare soil in a temperate humid climate-measurement using micro-lysimeters and time domain reflectometry. Agricultural and Forest Meteorology, Amsterdam, v.76, n.1, p.1-17, 1995.

Reichardt, K. Processos de transferência no sistema solo-plantaatmosfera. 4 ed. São Paulo: Fundação Cargill, 1985, 445p.

Santos, C.A.S. Distribuição espacial e absorção de água pelo sistema radicular da cultura da manga (Mangifera indica $\mathrm{L}$.) irrigada por microaspersão. Piracicaba: ESALQ/USP, 1997, 51p. Dissertação Mestrado

Singh, R.V.; Chauhan, H.S. Irrigation scheduling in wheat under shallow water table conditions. In: Evapotranspiration and irrigation scheduling, Proceedings of the International Conference, American Society of Agricultural Engineers the Irrigation Association, November, 3-6, San Antonio, Texas, p.104-109, 1996.

Souza, F.X.; Pinto, A.C.Q. Avaliação de cultivares de mangueira sob cultivo de sequeiro em Parnaíba, PI. Revista Brasileira de Fruticultura, Cruz das Almas, v.18, n.1, p.7-13, 1996.

Trambouze, W.; Bertuzzi, P.; Voltz, M. Comparison of methods for estimating actual evapotranspiration in a row-cropped vineyard. Agricultural and Forest Meteorology, Amsterdam, v.91, n.1, p.193-208, 1998.

van Genuchten, M.T. A colosed-form equation for predicting the hydraulic conductivity of unsaturad soils. Soil Science Society America Journal, Madison, v.44, p.892-898, 1980.

Vieira, S.R.; Castro, O.M. Determinação, em laboratório, de curvas de retenção de água com tensiômetros. Revista Brasileira de Ciência do Solo, Campinas, v.11, n.1, p.87-90, 1987.

Villagra, M.M.; Bacchi, O.O.S.; Tuon, R.L.; Reichardt, K. Difficulties of estimating evapotranspiration from the water balance equation. Agricultural and Forest Meteorology, Amsterdam, v.72, n.1, p.317-325, 1995. 